\title{
CHIROPODY AND SCIENTIFIC ATTITUDE
}

\author{
By Ernest J. Crossley, M.I.I.Ch. (N.S.W.), L.Ch. \\ - That which is looked upon by one generation as the apex of human knowledge is often con- \\ sidered an absurdity by the next, and that which is regarded as a superstition in one century \\ may form the basis of science for the following one.'-(Theophrastus Paracelsus, 1493)
}

\section{Knowledge and its historical significance}

Chiropody first came to the fore in about 1800 and also to base itself on the parent basic sciences. A corncutter in Davies Street, London, was the first to introduce the name chiropodist in 1785 . As old manuscripts have proved, for generations chiropodial treatment had been mainly carried out by barbers and bootmakers, who treated conditions of the hands as well as those of the feet. About I840 the corncutter no longer dealt with hands. A bootmaker, H. Levy, I886, wrote an interesting work on the care of the feet which he called 'Le Pedicure,' in which he described a mechanism of walking, which is completely opposed to that of Morton's Theory. He says: "In the act of walking the foot should reach the ground flat to the toes, and not the heel should reach first,' and further on he wrote: 'After all the foot is a feeler.'

One of the most important of all old chiropodial publications is the work of Heyman Lion ( 1800 ), 'A Treatise on Spinae Pedum'; mainly because of his originality it is unique, and is of historical significance. He was probably the first chiropodist who attempted a form of scientific investigation into the causation of the common corn, and also to define the condition. This author made microscopical examinations and also carried out chemical experiments. On this he writes: 'I then fell upon experiments for the investigation of the matter. I put spinae of various shapes and appearance into vitriolic acid.' He did this in the hopes of grouping and defining the corn. Thus the names spinae pedum, hereditario, pressa, projecta and fibrosa were given by. Heyman Lion, and were used by other authors up until 1878. The reason for giving it the name spina pedum is that it signifies a thorn, and a thorn in the feet he thought seemed applicable. The written work of D. Low ( 1802 ) is of important historical value, as are also the books by $\mathrm{C}$. $\mathrm{H}$. Clarke, Myer, J. Eisenberg, C. Montague and L. Durlacher. John Hunter (1845) classified corns as follows:

$$
\begin{array}{cl}
\text { Clavus durus } & \text {-hard corn } \\
, \quad \text { mollis } & \text { - soft corn }
\end{array}
$$

\section{niger -black corn
$" \quad$ sanguineus-bleeding corn}

Clavus or carpenter's nail, so called because a corn resembles a carpenter's nail driven into the flesh, whence the Latin name of clavus, a name under which it was designated by Celsus and other Roman authors.

Hippocrates, the founder of physics, on nails, said: 'Nails originate and are formed from the veins and arteries and cutis of the hand.' Aristotle's remark was "that the nails are derived from bone and flesh and that they are composed of both.' Gallen wrote: 'Nails receive their nourishment, sensation and life from the nerves, veins and and arteries.' Old French writers called warts 'porreau' or leeks. The Latins, 'verrucae formicariae' (flat warts) or, as they were likewise styled by the ancients, ' myrmecia.' In Scotland, conditions in the region of the first metatarsophalangeal joint were named 'vireck'; and in England, bunion, onion and spina projecta. The reason for this term appears evident as the part projected and was often covered with a corn.

\section{The value of knowledge}

Knowledge is power, and it is, therefore, valuable to man to advance civilization. Pasteur said ' the experimenter is the conqueror of Nature.' The chief concern of man has been with his environment, which he has dominated, and has attempted to control, investigate, and to use its forces. To achieve complete conquest of environment man must consent to think scientifically. Modern scientific knowledge was and is obtained by direct observation, depending upon the keen eye of the investigator, as science progresses so knowledge depends more and more upon scholarship. When one communicates with the modern writer or scientific explorer, one soon learns that the bulk of his knowledge is obtained through published works. The majority of progressive scientific writers deal with these observations of facts, and with experiments undertaken in the attempt to verify a hypothesis. Science is like a jigsaw puzzle without the pieces. The in- 
vestigator must explore for his pieces so as to make his part of the whole. For science in progress requires us to investigate the new or unexplored; or it may require a theory which modifies another, or ask us to look at a known phenomena in an entirely fresh and different way.

\section{Honesty of purpose}

When investigating a subject one must become ' depersonalized,' one must set oneself apart from the matter, and thus eliminate personal experience, one's own feeling, social environment, religion, and political followings: by applying one of these to a phenomenon it produces obscurities. Science remains aloof and detached, for its own sake. Science is concerned with science, not with commercialism, humanism, professionalism, capitalism or communism.

Professional medical bodies have made it their business to see that their members have a proper training, although their main object has been, and still is, to spread professional respectability. A popular delusion has been spread that the medical man and chiropodist are men of science. Chiropody and doctoring is an art. It is the art of healing and is based on the sciences, like architecture. We derive most of our ideas from scientific methods. The Greeks, the Roman Celsus and Paracelsus; all these great physicians have stated that medicine is an art. Incidentally, Paracelsus, the Swiss (born 1493), who renamed himself after the well-known Roman physician Celsus, whose equal he considered himself, was responsible for bringing about modern psychology and biochemistry.

\section{Psychological process}

It is the truth behind the phenomenon that matters. The whole of science is based on truths, if it were not so no progress would be made. It is the desire to get to the bottom of things and getting them into their proper perspective. Unless our skeleton knowledge is real it would be impossible to make an intelligible hypothesis. Huxley once said: 'A man of science should always be thinking new thoughts or seeking the material for new thoughts.' Conclusions come by the continuous thinking over of the facts; this will or may eventually in some way bring about an answer. This letting the mind play among the facts is an unconscious cerebral form of experimentation. An important conclusion may be reached by a flash of imaginative genius. In this way the artist gets his inspiration, it may be conscious or unconscious, or may be a mixture of both. An artist maintains that one stroke of the brush can be a work of art within itself, or that the stroke may be the making of a picture. So it is with science, that one thought; or the important observed fact, which may be the making, changing 3 or even the breaking of an important hypothesis. $\mathbb{Q}$ To make this more clear, I wish to put before you $C$ the words of a leading psycho-analyst, Ernest Jones, M.D., D.Sc., F.R.C.P.:

' This remarkable capacity for perceiving with somnambulic sureness what is absolutely and universally true, is of great interest. It transcends $\frac{\bar{s}}{\sigma}$ the simple love of truth itself, essential though this $\stackrel{\mathbb{Q}}{\triangle}$ may be. I think it must occur at special moments when there is an unusual, and often only tem- $\vec{O}$ porary, fusion of all elements in the mind in a peculiar degree of harmony. The sureness with $\vec{\omega}$ which the ego is receiving in an unquestioning fashion the message from the preconscious. At that moment there is a complete coincidence be- 3 tween the striving of the id, the permission of $\omega$ the super-ego, the acceptance by the ego and the $\dot{\omega}_{\infty}$ external perception of the problem being studied.'

\section{Chiropody in progress}

Man is living in a period in which his whole way $\stackrel{\circ}{?}$ of life is being changed. This new world to come $\vec{\theta}$ will be in the hands of the scientist and technologist. These rapid changes and progress are $\frac{0}{\circ}$ being made now. It is up to us younger chiropo- $\frac{\mathbb{D}}{-}$ dists to bring chiropody into this line of progress $\overrightarrow{0}$ to do this we must plan its investigation, we musit of apply scientific methods.

The State should make an allotment of State funds for chiropodial research. It is almost impossible for any one chiropodist in private practice to carry out any extensive form of investigation, $\frac{\mathscr{Q}}{\otimes}$ owing to his economic position. Private practice must come to an end within the next 40 years; $\overrightarrow{\bar{O}}$ therefore foot health and chiropody may be controlled and paid for, to an increasing extent, by the State. At the moment the foot health of the nation is in the hands of commercialism and pseudo-scientific groups. The late Sir Thomas Lewis, F.R.S., M.D., D.Sc., L1.D., a leading physician, said some years ago, 'Research is widely exploited for professional ends.'

There is widespread encouragement to the public to wear health shoes. A health shoe is one which allows the mechanics of the foot to operate and to control the shoe in the act of walking. The modern shoe indirectly controls the mechanics of $N$ the foot and its walking. Foot health groups $N$ should display a foot health shoe, but, alas, it does N not exist. As far as I know, no attempts are made $\omega$ to inspire the more progressive young chiropodist into any form of clinical research. He simply $\stackrel{\circ}{=}$ leaves the foot college, like a technician. He has $\stackrel{\odot}{\mathcal{D}}$ been trained to do a job. After qualification a chiropodist who shows promise and is scientifically 0 inclined should be encouraged to stay on at the 


\section{A new monograph entitled}

\section{Pulmonary Complications of Abdominal Surgery}

by ANTHONY R. ANSCOMBE, M.S.(Lond.), F.R.C.S.(Eng.)

Senior Lecturer in Surgery and

Honorary Consultant, St. George's Hospital

Surgeons, anaesthetists and physicians, who have care of patients after operation, cannot fail to be stimulated by the problem of post-operative pulmonary complications as described in this book. These all-too-frequent complications are shown to be due to the effect of the abdominal operation $C E$ the mechanical function of the lungs: an effect which may be so severe as to cause the deaths of some patients in the immediate post-operative period.
$x+121 p p$.
37 illustrations

(1957) 20s. net

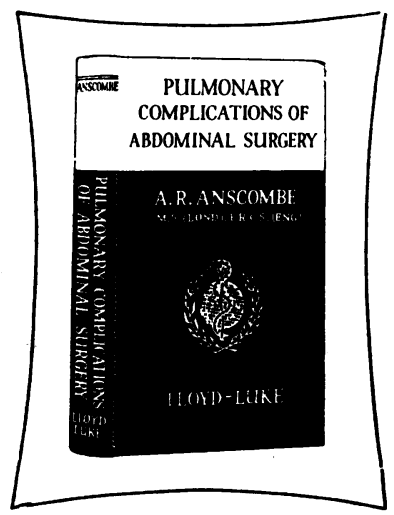

\section{An indispensable guide}

\section{Medical EThics}

edited by MAURICE DAVIDSON

D.M.(Oxon.), F.R.C.P.(Lond.)

Consulting Physician, Brompton Hospital
"In this book authoritative rulings are given by senior men on most of the problems met with in professional work." $x+165 p p$. 1 illustration (1957) 20s. net

Practitioner

\section{Lloyd-Luke (Medical Books) Ltd., 49, Newman Street, W.1}

foot clinic to carry out experimental and investigational work, thus familiarizing himself with various methods in an attempt to gain or bring about new knowledge. Such investigations should not be confined to the chiropody field alone but he should be permitted to visit medical schools and hospitals to gain a knowledge of their methods, especially on the laboratory side. Thus we would produce first-rate teachers who, in their turn, would bring about great changes in chiropody so that eventually chiropody would have its own specialized investigators.

As an example of investigational experimental chiropody, one could examine and explore the physiology and morphology and consider the treatment of the lower limbs of the anthropoids. Obviously such a project would have to be regarded as purely experimental; its feasibility could not be guaranteed at the onset. The nature and extent of the treatment to be adopted could only be ascertained after a preliminary survey of the animals and their living conditions, and the responsiveness of the animals themselves might also be regarded as an unknown factor. If a chiropodist were part of the routine veterinary service at the zoo, we would inevitably learn something about the foot conditions of the anthropoids, and perhaps be able to decide which complaints can be regarded as natural to the species con- cerned, and which, if any, are due to conditions of captivity. Such observations on, and treatment administered for foot complaints of anthropoids might prove of extreme value to the theory and practice of human chiropody.

Medicine has produced its own specialized fields or sciences, such as physiology, pathology and biochemistry. There is no reason why chiropody (in many years to come) should not bring about its own specialized branches. Its subdivisional fields would not necessarily follow the line of medicine, but rather chiropody will develop on similar lines to dentistry, although, however, like dentistry, we will always turn to medical investigators of various sources of knowledge.

I am grateful to Norman D. Kay, Ph.D., B.A., B.Sc., F.Inst.T.C., former lecturer at the Sydney Foot Clinic, because he first interested me in this realm of scientific thought. As a man of science and by his outstanding intellect he has inspired me; it is through his influence and association that $I$ have recorded these views.

\section{B IBLIOGRAPHY}

HARGREAVES, J. (1950), 'The Life and Sole of Paracelsus.' HUXLEY, J. (r926), 'Essays in Popular Science.' JONES, E. (1956), 'The Nature of Genius.' LEVY, H. (1886), ' Le Pedicure.'

LEWIS, T. (1956), 'Research in Medicine.'

LION, H. (1802), ' Treatise on Spinae Pedum.'

SHAW, G. B. (1911), 'Doctors Dilemma.'

THOMSON, J. A. (I9r6), 'Introduction to Science.' 